\title{
THE REMOVAL INVESTIGATION OF COCONUT ACID SURFACTANTS IN ACTIVATED SLUDGE'S SYSTEM
}

\author{
Baharan Moazzenipour', Alireza Salehpour', Batool Ahansazan², \\ Sohrabali Ghorbanian' ${ }^{\text {, Hamid Rashedi' }}$ \\ 1 School of Chemical Engineering, College of Engineering, University of Tehran, Tehran, Iran \\ 2 Faculty of Engineering, Department of Chemical Engineering, Valiasr Technical College, Tehran, Iran \\ * Corresponding author's e-mail: hrashedi@ut.ac.ir
}

Received: 2017.01.28

Accepted: 2017.03.07

Published: 2017.05.02

\begin{abstract}
There are significant municipal concerns relating to the use of surfactants and enzymes in the process of wastewater treatment. Treatment plants use different techniques to remove impurities from water.As wastewater treatment plants use the latest technology to remove contaminants from water, there are high costs, and sometimes an enforcement of regulations is lax. Still, many municipalities across the country prohibit the use of surfactants and enzymes entering wastewater treatment because of the harmful effects of these products on the sewer lines and high damage costs. Surfactant compounds are organic. Their molecules include water-soluble and oil or an insoluble component. These molecular compounds seek the water surface and chemically reduce the boundaries between oil and water. When surfactants are in the water, they absorb into the soil and can cause injury to plants and organic organisms, but people find surfactants and enzymes useful in cleaning agents for emulsifying and dispersing oil and grease. Scientists have found that at least some surfactants are toxic to ecosystems, people and animals, but they have not been able predict far-reaching consequences. And now the most important question is how to solve this problem or how to reduce these negative effects. In this paper we tried to remove surfactants from waste water with an activated sludge system.
\end{abstract}

Keywords: Cocamide DEA, surfactant, waste water, activated sludge, COD.

\section{INTRODOCTION}

Cocamide DEA, or Cocamide DI Ethanolamine is a DI ethanol amide made by reacting the mixture of fatty acids from coconut oils with DI Ethanolamine. It is a viscous liquid and is used as a foaming agent in bath products like shampoos and hand soaps, and in cosmetics as an emulsifying agent (See Cocamide for the discussion of the lengths of carbon chains in the molecules in the mixture). The chemical formula is $\mathrm{CH}_{3}\left(\mathrm{CH}_{2}\right)$ n $\mathrm{C}(=\mathrm{O}) \mathrm{N}\left(\mathrm{CH}_{2} \mathrm{CH}_{2} \mathrm{OH}\right)_{2}$, where $\mathrm{n}$ can vary depending on the source of fatty acids.

Three cases are reported by individuals allergic to Cocamide DEA, also known as coconut DI ethanol amide. In two cases, multiple other cutaneous allergies were present. In both instances, Cocamide DEA was present in several personal care products used by patients. In the third case, occupational exposure was suspected. Cocamide DEA is an unusual allergen that may cause contact dermatitis in individuals who often have multiple other skin allergies. The International Agency for Research on Cancer (IARC) lists coconut oil di ethanolamine condensate (Cocamide DEA) as an IARC Group 2B carcinogen, which identifies this chemical as possibly carcinogenic to humans. In June 2012, the California Office of Environmental Health Hazard Assessment added Cocamide DEA to the California Proposition 65 (1986) a list of chemicals known to cause cancer. 


\section{MATERIAL AND METHOD}

\section{Experiment}

In this experiment we used 4 bubbling stirred reactors. Three reactors contained activated sludge with surfactants (Cocamid DEA) with variance density 1000, 2000, $4000 \mathrm{ppm}$ and the forth one contained only activated sludge.

We used activated sludge for their more advantage; it is not expensive, does not have any danger for the environment and it is accessible. Activated sludge treatment is suitable for use in facilities that contain organic chemical waste. These may include municipal sewage treatment plants, oil refineries, food processing plants and chemical manufacturing At the first day each of the surfactant's reactors contained 4 gr of dry matters with distilled water free from additive. We aerated the reactors for 28 days.

\section{Prepration of activated sludge}

Activated sludge culture was received from wastewater treatment plant of Oil National Company in Tehran, Iran. The aerobic reactor was inoculated with this culture. The constituents of wastewater used throughout the studies are given in Table 1. Lack of each of these materials can limit the growth of microorganisms, of course, there are all of them in the wastewater, except phosphorus, nitrogen, carbon and oxygen are required that were added every day. In the starting test, first and second day the sludge settling time was two hours then the dead cells were collected. On the third day sludge feeding began. The amounts of feed were equal to glucose $7.5 \mathrm{gr} / \mathrm{day}$,
Ammonium phosphate 0.34 gr/day and Ammonium nitrate $0.93 \mathrm{gr} /$ day. The feeding was done for a week. So the culture was ready for testing.

\section{EXPERIMENTAL PROCEDURE}

We used four reactors with the same structure and volume as explained above in parallel tests. Experiments were started batch wise. Activated sludge from wastewater treatment plant was added to the reactors as seed. The similar value of sludge was inoculated in four parallel reactors. The test reactors (R1, R2 and R3) contained bio surfactant. The Cocamid DEA bio surfactant concentration was added to them, in 1000, 2000, 4000 ppm respectively. In the control reactor (R4), the feed water did not contain any surfactant in order to specify the effect of surfactant. Each of the test series dissolve in distilled water and make up 1 litter. The entire reactor was aerated by an air pump. These conditions were fixed for the entire duration of the experiment. The temperature and Pressure were $250{ }^{\circ} \mathrm{C}$ and $625 \mathrm{~mm} \mathrm{Hg}$ and $\mathrm{pH}$ adjusted to 7. A schematic diagram of the experimental setup is shown in Figure 2.

Table 1. Inorganic constituents of microorganisms

\begin{tabular}{|c|c|}
\hline Chemical Compounds & Percent \\
\hline $\mathrm{MgO}$ & 8 \\
\hline $\mathrm{K}_{2} \mathrm{O}$ & 6 \\
\hline $\mathrm{Fe}_{2} \mathrm{O}_{3}$ & 1 \\
\hline $\mathrm{P}_{2} \mathrm{O} 5$ & 50 \\
\hline $\mathrm{SO} 2$ & 15 \\
\hline $\mathrm{Na} 2 \mathrm{O}$ & 11 \\
\hline $\mathrm{CaO}$ & 9 \\
\hline
\end{tabular}

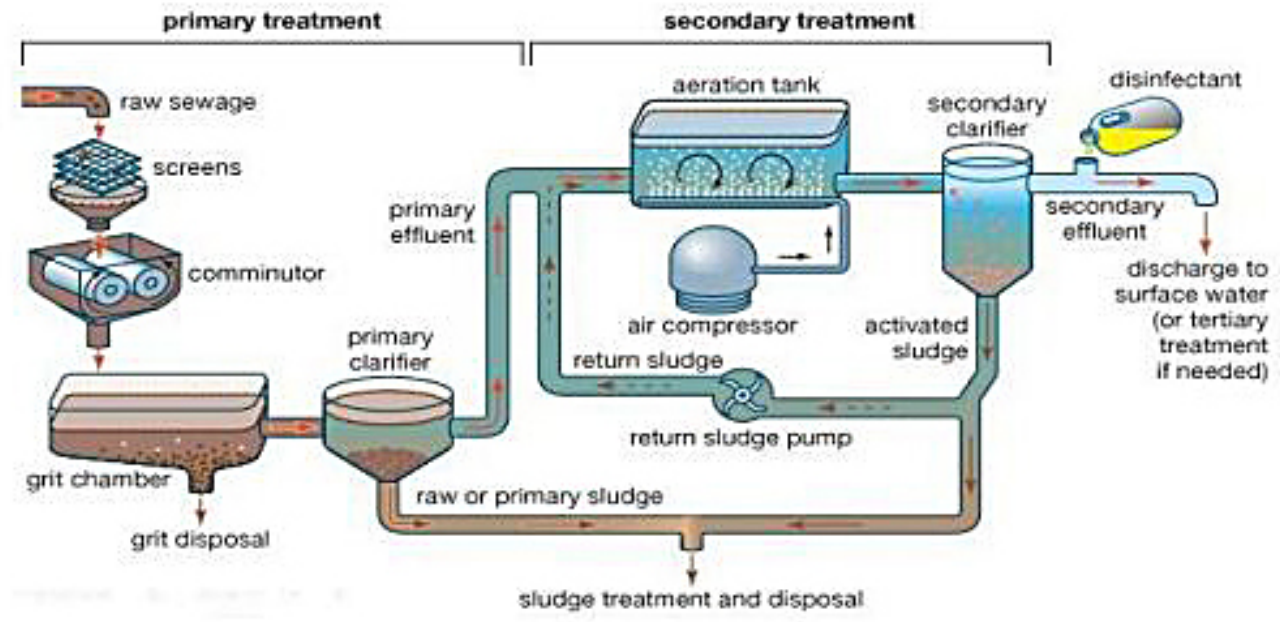

Figure 1. Activated sludge acquisition 


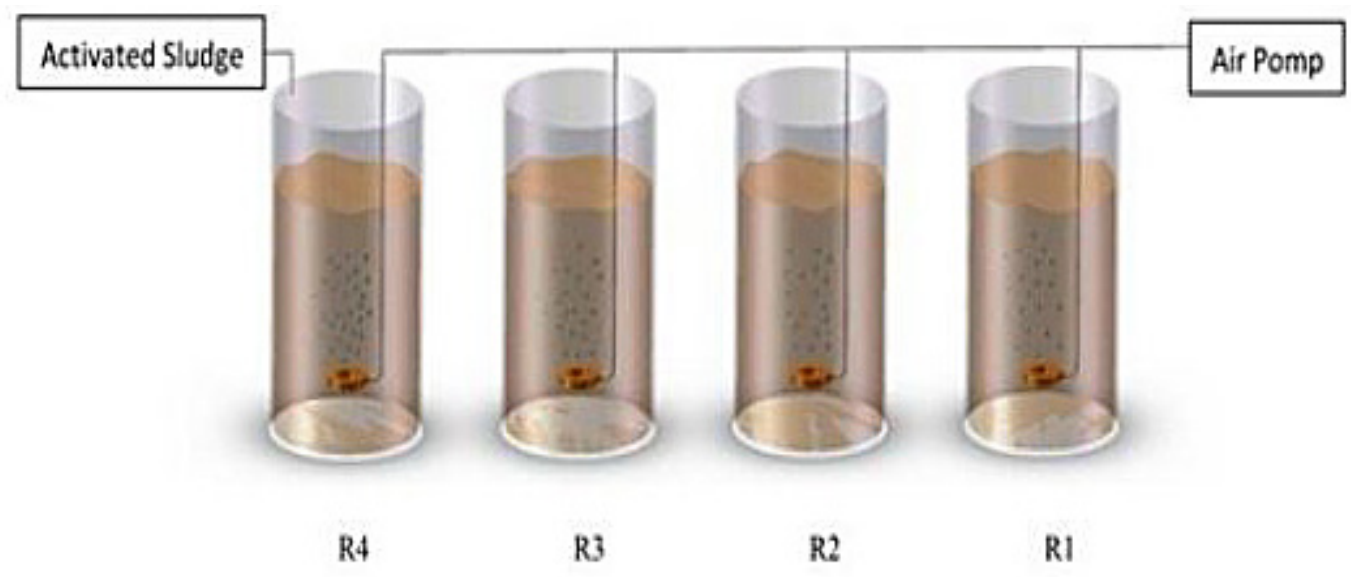

Figure 2. Schematic diagram of the experimental setup

\section{RESULTS AND DISCUSSION}

MLSS testing measures the total concentration of mixed liquor suspended (non-soluble) solids in the aeration basin of an activated sludge system. The mixed liquor suspended solids (MLSS) data are critical in determining the operational behavior and solids inventory of the system and it is used to determine when to waste and/or recycle sludge.

In order to test the mixed liquor suspended solids (MLSS) a well-mixed sample should be filtered through a weighed filter. The residue left on the filter is dried to a constant weight at a temperature between $103^{\circ} \mathrm{C}$ and $105^{\circ} \mathrm{C}$. The increase in weight of the filter represents the total suspended solids of the sample. The size of sampling should also be limited to a size the yields, no more than $200 \mathrm{mg}$ residue. After the mixed liquor suspended solids value is determined a mixed liquor volatile suspended solids (MLVSS) test may be per- formed in order to determine the concentration of volatile suspended solids in the aeration basin of an activated sludge system. Mixed liquor volatile suspended solids data are critical in determining the operational behavior and biological inventory of the system. The filter used for mixed liquor suspended solids (MLSS) testing is ignited at $550^{\circ} \mathrm{C}$ for 30 minutes. The weight lost on ignition of the solids represents the volatile solids in the sample. Figure 3 shows the rate of MLSS and MLVSS. During 28 days MLSS increased from $1.259 \mathrm{~g} / \mathrm{lit}$ to $1.299 \mathrm{~g} / \mathrm{lit}$ and MLVSS increased from $1.257 \mathrm{~g} /$ lit to $1.295 \mathrm{~g} /$ lit.

Biochemical oxygen demand (BOD) and chemical oxygen demand (COD) are two different parameters to measure how much oxygen the water will consume when it enters the recipient. In both cases the oxygen-consuming substances are mainly of organic origin. These substances should be reduced to a minimum in the waste-

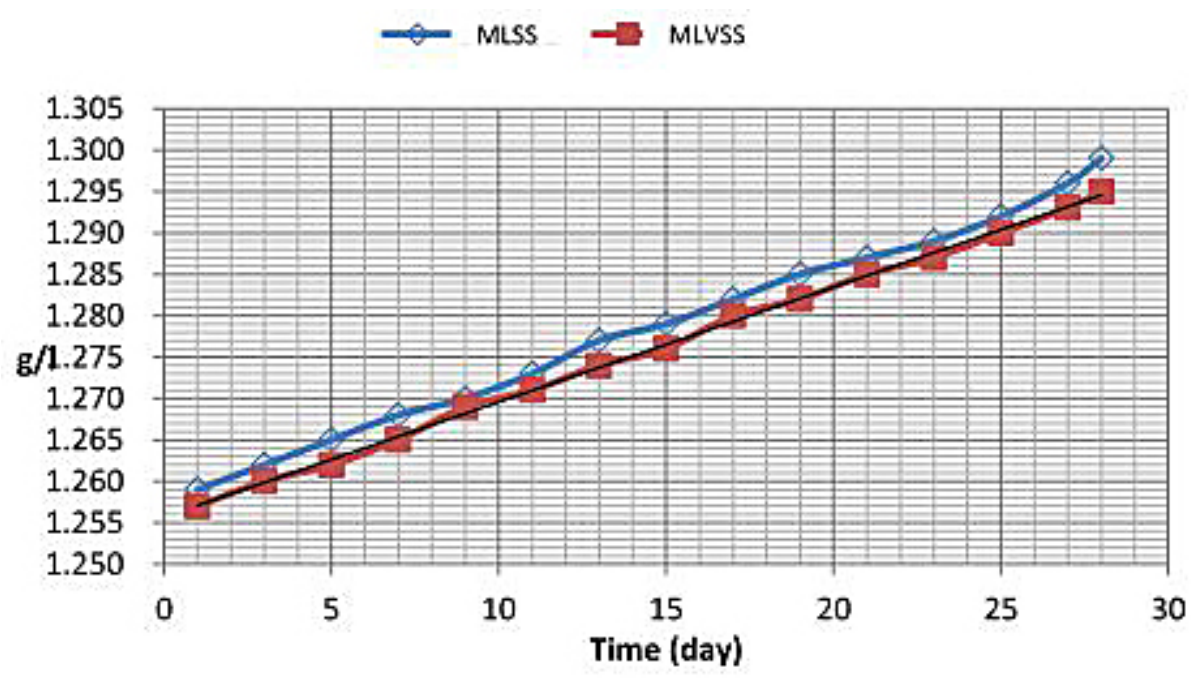

Figure 3. The rate of MLSS and MLVSS of activated sludge, during the test 
water treatment plant. Industries normally focus more on COD and municipalities than on BOD removal. With a chemical treatment, removal of COD is improved at basically all kinds of wastewater plants. The more particle-bound COD, the more efficient the removal rate. Our products can separate some dissolved substances as well, but when the COD consists of small organic molecules a biological treatment process is normally preferred. As shown in Table 2 in the 3 days, COD removal efficiencies were from $61 \%$ to $81 \%$ in the R1, it was from $1.3 \%$ to $48 \%$ in $\mathrm{R} 2$ and $12 \%$ to $24 \%$ in R3. The reduction was observed in the first week, equal to $95 \%$ in $\mathrm{R} 1,97 \%$ in $\mathrm{R} 2$ and $93 \%$ in $\mathrm{R} 3$.

Figure 4 depicts a shift of COD removal efficiency rates with time. Rapid slope increase in
COD removal efficiency rate with the time in R1, the high decreases in COD concentrations occur in the first 3 days. After that, the removal rate is linear. At the end of the test, the maximum removal was $95 \%$ after 14 days.

Figure 5 depicts shift of COD removal efficiency rates with time. Rapid slope increase in COD removal efficiency rate with the time in R2, the high decreases in COD concentrations occur in the first 3 days. After that, the removal rate is linear. At the end of the test, the maximum removal was $97 \%$ after 21 days.

Figure 6 depicts shift of COD removal efficiency rates with time. Rapid slope increase in COD removal efficiency rate with the time in R3, the high decreases in COD concentrations occur in the first 7 days. After that, the removal rate is

Table 2. Comparison of operational parameters of the reactors with different surfactant concentration

\begin{tabular}{|c|c|c|c|}
\hline Reactor & Run & Time (day) & COD Removal Efficiency \\
\hline \multirow{3}{*}{ R1 } & Run No.1 & 1 & $61 \%$ \\
& Run No.2 & 3 & $81 \%$ \\
& Run No.3 & 7 & $91 \%$ \\
& Run No.4 & 14 & $95 \%$ \\
\hline \multirow{3}{*}{ R2 } & Run No.1 & 1 & $1.3 \%$ \\
& Run No.2 & 3 & $48 \%$ \\
& Run No.3 & 7 & $86 \%$ \\
& Run No.4 & 14 & $91 \%$ \\
& Run No.5 & 21 & $97 \%$ \\
\hline \multirow{3}{*}{ R3 } & Run No.1 & 1 & $12 \%$ \\
& Run No.2 & 3 & $24 \%$ \\
& Run No.3 & 7 & $33 \%$ \\
& Run No.4 & 14 & $85 \%$ \\
& Run No.5 & 21 & $91 \%$ \\
& Run No.6 & 28 & $93 \%$ \\
\hline
\end{tabular}

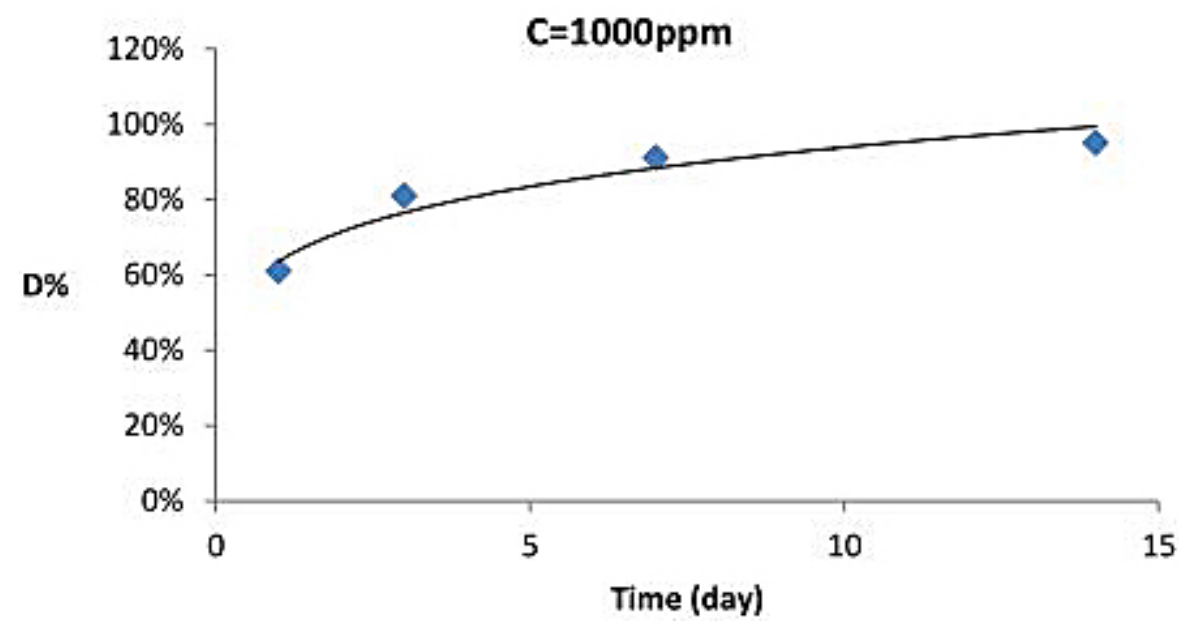

Figure 4. Shift of COD volumetric removal rates with overtime for $\mathrm{C}=1000 \mathrm{ppm}$ 


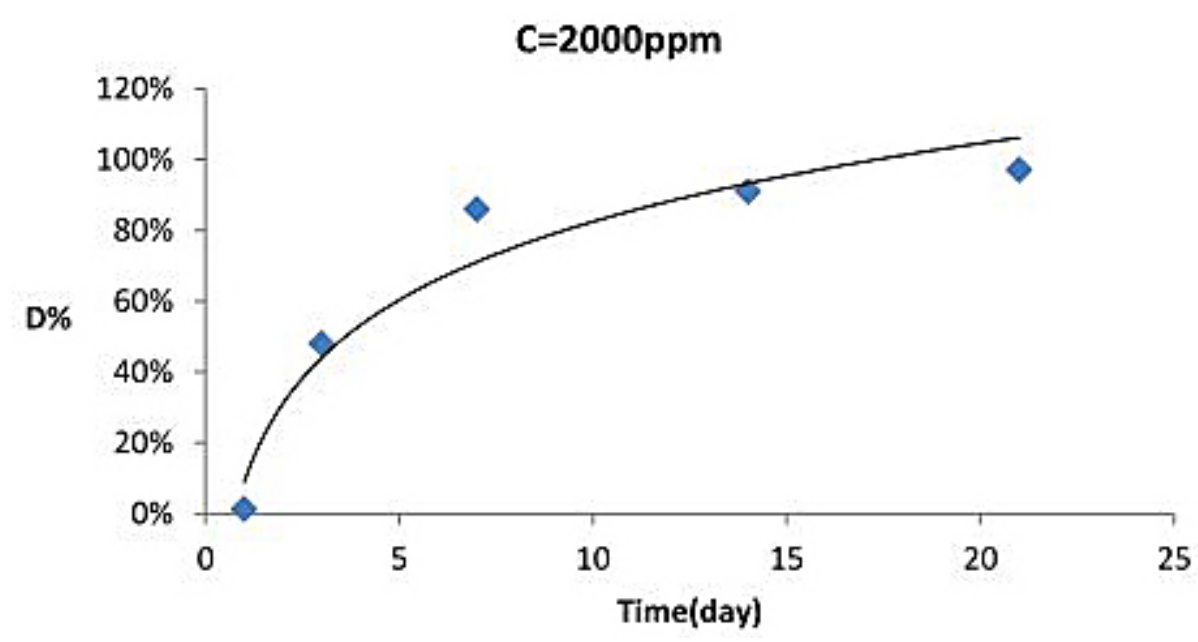

Figure 5. Shift of COD volumetric removal rates with overtime for $\mathrm{C}=2000 \mathrm{ppm}$

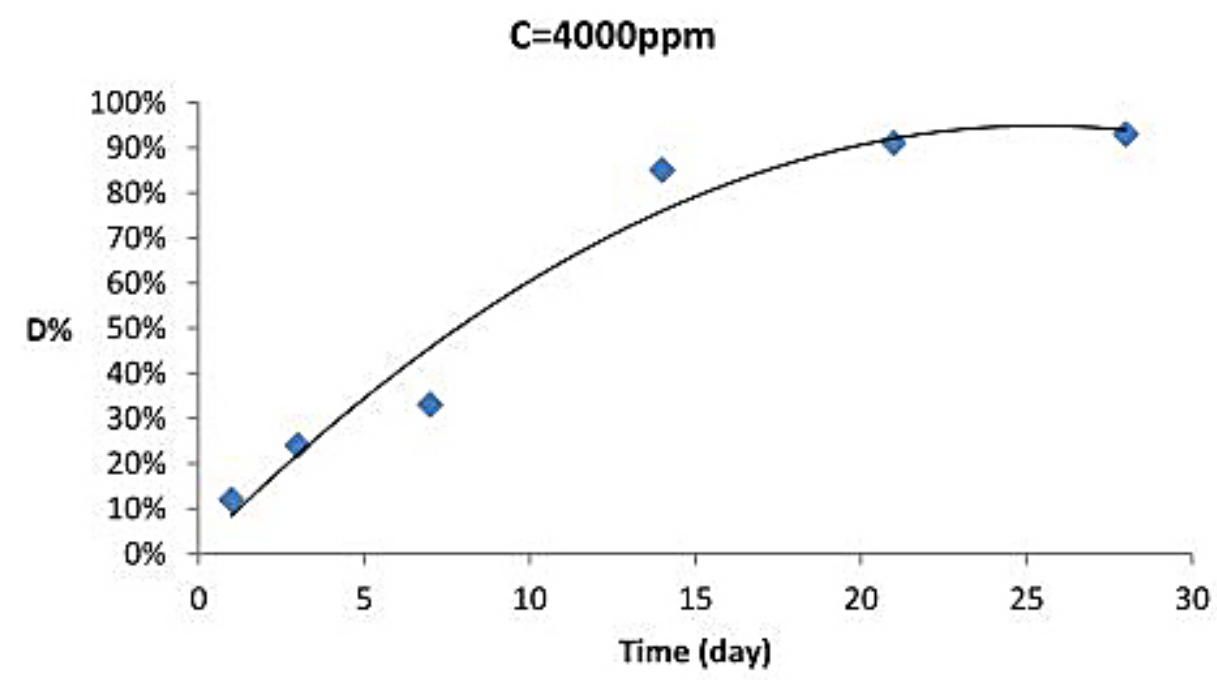

Figure 6. Shift of COD volumetric removal rates with overtime for $\mathrm{C}=4000 \mathrm{ppm}$

linear. At the end of the test, the maximum removal was $93 \%$ after 28 days.

\section{CONCLUSION}

In this paper, the authors investigated the impact of Cocamide DEA on the activated sludge system of biological treatment. Increasing the concentration of surfactant would lead to treatment plant efficiency enhance. Also the result showed that increasing the concentration of solids MLSS makes the removal efficiency increase.

According to the result of this study, it can be complete, proven by further investigations that bio surfactant-enhance degradation would result in prompter (reduced treatment times) and modified water quality, and overall cheaper treatment cost. The interaction between bio surfactant and the pollution in wastewater is a very complex phenomenon and is not the subject of this study. But it is possible to say that bio surfactants are very effective in the COD removal as demonstrated in this study. So, the effectiveness of different bio surfactants in the removal of more pollutions should be investigated in the future studies in order to distinguish the best combination.

\section{REFERENCES}

1. Chen, Chun Yun, and Yuan Yi Zhuang. 2009. Adsorbent derived from sewage sludge and its application in dye wastewater treatment. 3rd International Conference on Bioinformatics and Biomedical Engineering. IEEE, 2009.

2. Chen, Yinguang, A.A. Randall, and T. McCue. 2004. The efficiency of enhanced biological phosphorus removal from real wastewater affected by 
different ratios of acetic to propionic acid. Water Research 38(1), 27-36.

3. Chen, Yinguang, Haizhen Yang, and Guowei Gu. 2001. Effect of acid and surfactant treatment on activated sludge dewatering and settling. Water Research 35(11), 2615-2620.

4. Eichhorn, P. et al. 2000. Fate of surfactants and their metabolites in waste water treatment plants. Vom Wasser 95, 245-268.

5. Feijtel, T.C.J., et al. 1995. AIS/CESIO environmental surfactant monitoring programme. Part 1: LAS monitoring study in "de Meern" sewage treatment plant and receiving river Leidsche Rijn. Chemosphere 30(6), 1053-1066.

6. Forster, C.F. 1971. Activated sludge surfaces in relation to the sludge volume index. Water Research 5(10), 861-870.

7. Johnson, A.C., and J.P. Sumpter. 2001. Removal of endocrine-disrupting chemicals in activated sludge treatment works. Environmental Science \& Technology 35(24), 4697-4703.

8. Jiang, Su, et al. 2007. Biological short-chain fatty acids (SCFAs) production from waste-activated sludge affected by surfactant. Water Research 41(14), 3112-3120.

9. González S., M. Petrovic, and D. Barceló. 2004. Simultaneous extraction and fate of linear alkylbenzene sulfonates, coconut diethanol amides, nonylphenol ethoxylates and their degradation products in wastewater treatment plants, receiving coastal waters and sediments in the Catalonian area (NE Spain). Journal of Chromatography A 1052(1), 111-120.

10. Moghe, Pramod Prabhakar, et al. Process for treatment of mixture of spent wash from distillery and black liquor from pulp and paper industry. U.S.
Patent No. 6,589,427. 8 Jul. 2003.

11. Nakada, Norihide, et al. 2006. Pharmaceutical chemicals and endocrine disrupters in municipal wastewater in Tokyo and their removal during activated sludge treatment. Water Research 40(17), 3297-3303.

12. Pandit, P., and S. Basu. 2004. Removal of ionic dyes from water by solvent extraction using reverse micelles. Environmental Science \& Technology 38(8), 2435-2442.

13. Rosen, M.J., and J.T. Kunjappu. 2012. Surfactants and interfacial phenomena. John Wiley \& Sons.

14. Seviour, R.J., Takashi Mino, and Motoharu Onuki. 2003. The microbiology of biological phosphorus removal in activated sludge systems. FEMS Microbiology Reviews 27(1), 99-127.

15. Scott, M.J., and M.N. Jones. 2000. The biodegradation of surfactants in the environment. Biochimica et Biophysica Acta (BBA)-Biomembranes 1508(1), 235-251.

16. Shaffer, K.K., et al. 2006. Allergenicity and CrossReactivity of Coconut Oil Derivatives: A DoubleBlind Randomized Controlled Pilot Study. Dermatitis 17(2), 71-76.

17. Tong, Juan, and Yinguang Chen. 2007. Enhanced biological phosphorus removal driven by shortchain fatty acids produced from waste activated sludge alkaline fermentation. Environmental Science \& Technology 41(20), 7126-7130.

18. Wei, Yuansong, et al. 2003. Minimization of excess sludge production for biological wastewater treatment." Water Research 37(18), 4453-4467.

19. Yuan, Hongying, et al. 2006. Improved bio production of short-chain fatty acids (SCFAs) from excess sludge under alkaline conditions. Environmental Science \& Technology 40(6), 2025-2029. 